Wendy O. Henderson, MD

Associate Chief of Staff, Ambulatory Care

Service, Durham VA Health Care System;

Assistant Professor, Department of Medicine,

Duke University, Durham, NC
Mary H. Parker, PharmD, FASHP,

FCCP, BCPS, BCCP

Acting Chief Medical Officer, VA Mid-Atlantic

Health Care Network (VISN6); Clinical Coordina-

tor/Clinical Pharmacy Specialist, Pharmacy

and Ambulatory Care, Durham VA Health Care

System, Durham, NC
Bryan C. Batch, MD, MHS

Endocrine Section Chief, Durham VA Health Care

System; Associate Professor of Medicine, Duke

University Division of Endocrinology, Durham, NC

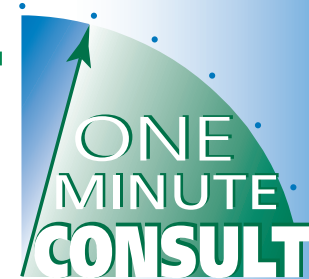

BRIEF ANSWERS

TO SPECIFIC

CLINICAL

QUESTIONS

\title{
: How should you assess glycemic control if the hemoglobin A1c is inaccurate or uninterpretable?
}

\begin{abstract}
A:
For adult outpatients with type 2 diabetes mellitus, hemoglobin A1c is the standard test used to gauge overall glycemic control during the previous 2 to 3 months and to titrate antidiabetic medications. But hemoglobin A1c does not provide an accurate assessment of frequency or severity of hypoglycemic events. Also, in some instances it may not truly represent glucose control, reflecting an average of high and low blood sugar values, or may not be reportable because of abnormal hemoglobin.

In these situations, an alternative test can be used along with capillary blood glucose testing, which remains the most reliable method of assessing glucose control in the short term. If an alternative test is used, it is important to clearly document it in the chart to reduce confusion, and also to educate the patient to better understand the disease-monitoring process.
\end{abstract}

\section{HEMOGLOBINOPATHIES CAN INTERFERE WITH HEMOGLOBIN A1C}

Many conditions that modify red blood cell production, destruction, or life span can affect the accuracy of hemoglobin A1c measurement (Table 1). ${ }^{1-8}$

Hemoglobinopathies can interfere with hemoglobin A1c testing, but this has become less of an issue as more laboratories use highperformance liquid chromatography in routine practice. The National Glycohemoglobin Standardization Program has published a list of commonly used hemoglobin A1c assays and expected interference from hemoglobin vari-

doi:10.3949/ccjm.88a.19135 ants. ${ }^{1}$ If the assay your laboratory uses is affected by these hemoglobin variants, consider other tests to measure long-term glucose control.

Suspect that a hemoglobinopathy or other condition is causing unreliable hemoglobin A1c readings if the hemoglobin A1c value ${ }^{1-6}$ :

- Does not correlate with the expected value based on capillary blood glucose readings or laboratory plasma glucose readings

- Is inconsistent with frequently sampled plasma glucose values

- Is greater than $15 \%$

- Changes significantly after the laboratory changes its testing method.

\section{ALTERNATIVE METHODS TO ASSESS LONG-TERM GLYCEMIC CONTROL}

Alternative tests to assess glycemic control include capillary blood glucose readings, continuous glucose monitoring, serum fructosamine, glycated albumin, and 1,5-anhydroglucitol.

\section{Capillary blood glucose}

Results from capillary blood glucose tests show glucose levels at a specific time and can be taken multiple times during a day. They are useful to identify glucose trends and inform medication adjustments.

This is the most common method to detect hypoglycemia and quantify its severity and frequency. Detecting hypoglycemia is especially important in patients receiving insulin or secretagogues or with other conditions that may predispose them to hypoglycemia. The hemoglobin A1c level can be above goal even if they have hypoglycemia. Capillary blood glucose monitoring relies on patient
Hemoglobin A1c is the standard but it is not perfect; alternatives are available 


\section{TABLE 1}

\section{Common clinical conditions that can affect hemoglobin A1c ${ }^{\text {a }}$}

\begin{tabular}{|c|c|c|}
\hline Clinical condition & Effect on hemoglobin A1c & Mechanism or reason for effect \\
\hline Asplenia & Increases hemoglobin A1c & $\begin{array}{l}\text { Decreased red blood cell (RBC) turnover due to increased } \\
\text { RBC life span }\end{array}$ \\
\hline \multirow[t]{2}{*}{ Chronic kidney disease } & \multirow[t]{2}{*}{$\begin{array}{l}\text { Effects vary based on } \\
\text { severity of underlying disease } \\
\text { and therapies }\end{array}$} & $\begin{array}{l}\text { Increased hemoglobin A1c } \\
\text { Carbamyl-hemoglobin production in uremic patients } \\
\text { Erythropoietin deficiency }\end{array}$ \\
\hline & & $\begin{array}{l}\text { Decreased hemoglobin A1c } \\
\text { Shortened RBC survival } \\
\text { Erythropoietin administration } \\
\text { Hemodialysis (lowering of urea levels reduces } \\
\text { carbamyl-hemoglobin concentration) }\end{array}$ \\
\hline \multirow[t]{2}{*}{ Chronic liver disease } & \multirow[t]{2}{*}{$\begin{array}{l}\text { Effects vary based on } \\
\text { severity of underlying disease } \\
\text { and therapies }\end{array}$} & $\begin{array}{l}\text { Increased hemoglobin A1c } \\
\text { Jaundice (increased glycation reaction in the presence } \\
\text { of higher bilirubin concentrations) }\end{array}$ \\
\hline & & $\begin{array}{l}\text { Decreased hemoglobin A1c } \\
\text { Increased RBC turnover } \\
\text { Antiviral drug therapies may decrease RBC life span }\end{array}$ \\
\hline Hemoglobinopathies & $\begin{array}{l}\text { Varies with testing method and } \\
\text { assay }\end{array}$ & Multifactorial including anemia and rapid RBC turnover \\
\hline \multirow[t]{2}{*}{ Hemolytic anemia } & \multirow[t]{2}{*}{ Decreases hemoglobin A1c } & Reduced RBC total volume \\
\hline & & Increased RBC destruction shortens RBC life span \\
\hline \multirow[t]{2}{*}{ Iron deficiency anemia } & \multirow[t]{2}{*}{ Increases hemoglobin A1c } & Reduced RBC turnover prolongs RBC survival \\
\hline & & $\begin{array}{l}\text { Greater malondialdehyde concentrations increase hemo- } \\
\text { globin glycation reactions }\end{array}$ \\
\hline \multirow[t]{4}{*}{ Pregnancy } & \multirow{2}{*}{$\begin{array}{l}\text { Decreases hemoglobin A1c } \\
\text { in first } 2 \text { trimesters }\end{array}$} & Increased RBC turnover decreases hemoglobin A1c \\
\hline & & Increased erythropoietin production decreases hemoglobin \\
\hline & \multirow{2}{*}{$\begin{array}{l}\text { May increase hemoglobin A1c } \\
\text { in third trimester }\end{array}$} & A1c \\
\hline & & Hemodilution decreases hemoglobin A1c \\
\hline \multirow[t]{2}{*}{ Transfusion } & \multirow[t]{2}{*}{ Variable hemoglobin A1c effects } & $\begin{array}{l}\text { Increased hemoglobin A1c } \\
\text { Elevated glucose concentration in storage medium }\end{array}$ \\
\hline & & $\begin{array}{l}\text { Decreased hemoglobin A1c } \\
\text { Dilutional response }\end{array}$ \\
\hline
\end{tabular}

Vitamin $B_{12}$ and folate Increases hemoglobin A1C

Reduced RBC turnover prolongs RBC survival deficiency anemias aThis summation represents most current literature and clinical practice, but should be used as a guide only and should not replace clinical assessment or
decision-making. 
adherence to checking and recording glucose values several times a day and communicating the results to the care team.

The American Diabetes Association suggests using the estimated average glucose lev$\mathrm{el}$, as calculated from the hemoglobin A1c, to give patients a reference to compare with the capillary blood glucose values they get at home. The formula is as follows':

Estimated average glucose $(\mathrm{mg} / \mathrm{dL})=$

$28.7 \times$ hemoglobin A1c (\%) - 46.7

For example if the hemoglobin A1c is 7\%, the estimated average glucose value would be $28.7 \times 7-46.7=154 \mathrm{mg} / \mathrm{dL}$. The American Diabetes Association has a conversion calculator on its website. ${ }^{10}$

\section{Continuous glucose monitoring}

Continuous glucose monitors measure interstitial glucose levels and are used to assess glucose trends over days to weeks. There are 2 main categories of these monitors: personal and professional. ${ }^{11,12}$ Personal monitors are typically worn long-term for patient self-monitoring and come in 2 major types: real-time and intermittently scanned. Health insurance coverage requires specific criteria to be met for approval of either type.

In contrast, a professional continuous glucose monitor, if covered by insurance, is typically used for a shorter time, after which a medical professional retrieves the results. Results are either displayed in real time to the patient or are blinded to the patient.

Personal and professional monitors have shown similar performance qualities. However, both are less reliable for detecting hypoglycemia events than capillary blood glucose readings. In addition, their accuracy depends on reliable sensor placement and avoidance of certain prescribed and over-the-counter medications. Moreover, their use has not been studied in patients with end-stage liver or kidney disease, and they should be used cautiously in patients who have any condition that could affect measurement of interstitial glucose.

\section{Serum fructosamine}

Serum fructosamine, a circulating glycated protein (mostly albumin), can be measured to monitor glycemic control when hemoglobin
A1c testing is inaccurate. Fructosamine levels provide an estimate of the average blood glucose levels in the preceding 7 to 21 days. This substance can be used to monitor rapid insulin titrations and has been shown to correlate more consistently with continuous glucose monitoring than hemoglobin A1c. ${ }^{13-15}$

Several formulas can be used to estimate the hemoglobin A1c based on the fructosamine level, eg:

$$
\text { Hemoglobin A1c (\%) = }
$$

$0.017 \times$ fructosamine level $(\mu \mathrm{mol} / \mathrm{L})+1.61$

By this formula, a fructosamine level of $317 \mu \mathrm{mol} / \mathrm{L}$ converts to a hemoglobin A1c of $7 \%$; a value of $375 \mu \mathrm{mol} / \mathrm{L}$ converts to a hemoglobin A1c of $8 \% .{ }^{16}$

However, in patients with conditions associated with altered albumin metabolism, such as nephrotic syndrome, advanced liver disease, or protein-losing enteropathy, the correlation between fructosamine levels and glycemic control may be decreased. ${ }^{14,15}$ Some suggest using a correction factor for the general equation, such as multiplying the fructosamine level by 4 and then dividing by the serum albumin level, but this practice has not been widely adopted. ${ }^{2,15}$

Pregnancy is another condition in which fructosamine levels have limited use. In this situation, other tests, such as capillary blood glucose or continuous glucose monitoring, may have better validity and clinical applicability.

\section{Glycated albumin}

This is an emerging measure that may improve the overall predictive value of glycemic control. The proportion of serum albumin that is glycated provides an estimate of glycemic control in the previous 14 to 21 days. This value is easily converted to an approximate hemoglobin A1c value by dividing by 3 . This is more straightforward than converting fructosamine to hemoglobin A1c and may provide better information regarding postprandial glucose values. ${ }^{17}$

However, glycated albumin values may not be reliable in patients with conditions that alter albumin metabolism such as nephrotic syndrome, hypo- or hyperthyroidism, or cirrhosis. ${ }^{13}$

\section{Hemoglobin A1c does not detect hypoglycemic episodes}




\section{1,5-Anhydroglucitol}

1,5-Anhydroglucitol is a dietary polyol that competes with glucose for reabsorption in the renal tubule when circulating glucose concentrations are elevated. Lower circulating serum concentrations of 1,5-anhydroglucitol correspond with increased glycosuria and hyperglycemia within the previous 7 to 14 days. ${ }^{18,19}$

This test is not as reliable in patients with altered renal perfusion, though it provides valuable information in assessing same-day periods of hyperglycemia, particularly glucose values greater than $180 \mathrm{mg} / \mathrm{dL}$. Also, 1,5-anhydroglucitol is not a reliable indicator of glucose control in patients on sodium-glucose cotransporter 2 inhibitors, which increase glycosuria. ${ }^{20}$

\section{EDUCATING PATIENTS AND PROVIDERS ON ALTERNATIVE TESTS}

Healthcare providers need to know that hemoglobin A1c does not correlate with capillary or venous blood glucose levels in some situations-otherwise, one might inappropriately escalate or de-escalate therapy. If alternative tests are used because of inaccurate or uninterpretable hemoglobin A1c values, clinicians need to document the clinical rationale. This documentation may prevent a hemoglobin A1c test from being ordered and falsely interpreted.

Patient education is also important. Suc-

\section{measurements}

\section{REFERENCES}

1. NGSP. HbA1c assay interferences. Accessed January 22, 2021. http://www.ngsp.org/interf.asp.

2. Radin MS. Pitfalls in hemoglobin A1c measurement: when results may be misleading. J Gen Intern Med 2014; 29(2):388-394. doi:10.1007/s11606-013-2595-x

3. American Diabetes Association. 2. Classification and diagnosis of diabetes: standards of medical care in diabetes-2020. Diabetes Care 2020; 43(suppl 1):S14-S31 doi:10.2337/dc20-S002

4. Lacy ME, Wellenius GA, Sumner AE, et al. Association of sickle cell trait with hemoglobin A1c in African Americans. JAMA 2017; 317(5):507-515. doi:10.1001/jama.2016.21035

5. Blendea MC, Thompson MJ, Malkani S. Diabetes and chronic liver disease: etiology and pitfalls in monitoring. Clin Diabetes 2010: 28(4):139-144. doi:10.2337/diaclin.28.4.139

6. Spencer DH, Grossman BJ, Scott MG. Red cell transfusion decreases hemoglobin A1c in patients with diabetes. Clin Chem 2011; 57(2):344-346.

doi:10.1373/clinchem.2010.15732

7. Fayyaz B, Rehman HJ, Minn H. Interpretation of hemo- cessful diabetes education efforts have led to widespread recognition of hemoglobin A1c as the standard diagnostic test for monitoring glycemic control. If a different test is used, the practitioner needs to explain the rationale to the patient and provide education on the alternative method. A diabetes educator, clinical pharmacist, or nurse may be able to facilitate this education.

If the patient has an abnormal hemoglobin variant, it should be added to the problem list. Consider adding ICD-10 code D58.2 (abnormal hemoglobin not otherwise specified) or D58 (other hereditary hemolytic anemias). Each facility can consider development and implementation of specific solutions.

Finally, insurance companies and other groups focused on quality metrics need to be informed of the inaccuracy of hemoglobin A1c testing for individual patients. With so many groups transitioning to population health data, a missing or inaccurate hemoglobin A1c test may affect the ability to assess glycemic control across a patient population and could affect assessment of performance measures for individual clinicians and practice groups. If data sets are automatically abstracted, the auditing software can penalize providers for not having tested hemoglobin A1c as a fundamental component of diabetes management.

\section{DISCLOSURES}

The authors report no relevant financial relationships which, in the context of their contributions, could be perceived as a potential conflict of interest.

globin A1C in primary care setting. J Community Hosp Intern Med Perspect 2019; 9(1):18-21. doi:10.1080/20009666.2018.1559432

8. Hellman R. When are HBA1c values misleading? AACE Clin Case Reports 2016; 2(4):e377-e379. doi:10.4158/EP161209.CO

9. Nathan DM, Kuenen J, Borg R, Zheng H, Schoenfeld D, Heine RJ; A1c-Derived Average Glucose Study Group. Translating the $\mathrm{A} 1 \mathrm{C}$ assay into estimated average glucose values. Diabetes Care 2008; 31(8):1473-1478. doi:10.2337/dc08-0545

10. American Diabetes Association. eAG/A1C conversion calculator. Accessed January 22, 2021. https://professional. diabetes.org/diapro/glucose_calc

11. American Diabetes Association. 7. Diabetes technology: standards of medical care in diabetes-2020. Diabetes Care 2020; 43(suppl 1): S77-S88. doi:10.2337/dc20-S007

12. Moser O, Pandis M, Aberer F, et al. A head-to-head comparison of personal and professional continuous glucose monitoring systems in people with type 1 diabetes: hypoglycaemia remains the weak spot. Diabetes Obes Metab 2019; 21(4):1043-1048. doi:10.1111/dom.13598

13. Lee JE. Alternative biomarkers for assessing glycemic control in diabetes: fructosamine, glycated albumin, 
and 1,5-anhydroglucitol. Ann Pediatr Endocrinol Metab 2015; 20(2):74-78. doi:10.6065/apem.2015.20.2.74

14. Kunika K, Itakura M, Yamashita K. Correction of fructosamine value for serum albumin and globulin concentrations. Diabetes Res Clin Pract 1991; 13(1-2):37-44. doi:10.1016/0168-8227(91)90031-8

15. Danese E, Montagnana M, Nouvenne A, Lippi G. Advantages and pitfalls of fructosamine and glycated albumin in the diagnosis and treatment of diabetes. J Diabetes Sci Technol 2015; 9(2):169-176. doi:10.1177/1932296814567227

16. Kang DS, Park J, Kim JK, Yu J. Clinical usefulness of the measurement of serum fructosamine in childhood diabetes mellitus. Ann Pediatr Endocrinol Metab 2015; 20(1):21-26. doi:10.6065/apem.2015.20.1.21

17. Koga M, Murai J, Morita S, Saito H, Kasayama S. Comparison of annual variability in $\mathrm{HbA} 1 \mathrm{C}$ and glycated albumin in patients with type 1 vs. type 2 diabetes mellitus. J Diabetes Complications 2013; 27(3):211-213. doi:10.1016/j.jdiacomp.2012.12.001

18. Buse JB, Freeman JL, Edelman SV, Jovanovic L, McGill JB. Serum 1,5-anhydroglucitol (GlycoMark): a short-term glycemic marker. Diabetes Technol Ther 2003; 5(3):355363. doi:10.1089/152091503765691839

19. Dungan KM. 1,5-anhydroglucitol (GlycoMark) as a marker of short-term glycemic control and glycemic excursions. Expert Rev Mol Diagn 2008; 8(1):9-19. doi:10.1586/14737159.8.1.9

20. Kalra S. Sodium glucose co-transporter-2 (SGLT2) inhibitors: a review of their basic and clinical pharmacology. Diabetes Ther 2014; 5(2):355-366. doi:10.1007/s13300-014-0089-4

Address: Mary H. Parker, PharmD, FASHP, FCCP, BCPS, BCCP Pharmacy and Ambulatory Care, Durham VA Health Care System, 508 Fulton Street (11-C), Durham, NC 27705; mary.h.parker@gmail.com 